\title{
KEANEKARAGAMAN JENIS GULMA BERDAUN LEBAR PADA PERTANAMAN JAGUNG (Zea mays L.) DI DESA SANGATTA SELATAN KABUPATEN KUTAI TIMUR
}

\author{
(Diversity of broadleaf weeds species in corn plantation at Sanggatta Selatan Village, Kutai Timur
}

Regency)

\author{
RUSDI RUSDI ${ }^{1}$, ZAINUDDIN SALEH ${ }^{2}$, RAMLAH RAMLAH ${ }^{2}$ \\ ${ }^{1}$ Program Pasca Sarjana Pertanian Tropika Basah, Universitas Mulawarman, Samarinda, Kalimantan \\ Timur Indonesia, Jln. Krayan Kampus Gunung Kelua, Samarinda, Kalimantan Timur Indonesia \\ ${ }^{2}$ Program Studi Agroteknologi, Sekolah Tinggi Pertanian (STIPER) Kutai Timur, Jl. Soekarno-Hatta \\ No. 01 Sangatta Kabupaten Kutai Timur, Kalimantan Timur \\ Email: rusdikutim82@gmail.com HP : 085246968118
}

\begin{abstract}
Diversity of broadleaf weeds species in corn plantation was the background for this research. The aims of this research to determine the Diversity of Broadleaf Weed Species at corn (Zea mays L.) plantation, at Desa Sangatta Selatan, Kabupaten Kutai Timur.This research used a square method, which is manufacture of plots with a zise $2 \times 2 \mathrm{~m}$ as much as 9 plots. Weeds found in the plot were identified and subsequently performed the calculation of aech species in each plot. The results showed that founded 11 species in 10 families. The highest dominance value in sequence, that is: Hedyotis corymbosa $L$. (28,03\%), Phyllantus niruri Klein ex Willd. (16.97\%), Ageratum conyzoides $L$. (12.40\%). and the lowest are: Hyptis capitata Jacq. (1,59\%). Weed diversity is heterogeneous, which means there is no one Broadleaf Weed Species was the dominance value of more than $80 \%$. Further research required regarding diversity grass weed classes and nut grass was founded on corn plantation in a wider scale and the effect on corn production.
\end{abstract}

Keywords : diversity of species, weeds, corn plantation.

\section{PENDAHULUAN}

Kabupaten Kutai Timur mempunyai potensi pertanian khususnya tanaman jagung yang sangat besar untuk dikembangkan. Pada tahun 2009 luas lahan produksi jagung mencapai 590 ha dengan jumlah penduduk yang bekerja di sektor pertanian sebesar $52,46 \%$ dari total jumlah penduduk Kutai Timur (Badan Pusat Statistik Kutai Timur, 2011). Produksi jagung selama tahun 2009 turun $36.03 \%$ mencapai 1.227 ton jagung pipilan kering panen dibanding produksi tahun 2008 sebesar 1.918 ton. Kemudian tahun 2010 mencapai 1.599 ton, namun produksi jagung selama tahun 2011 hingga pada angka ramalan III di Kabupaten Kutai Timur sebesar 1.173 ton. Dengan demikian turun sebesar 36\% dibandingkan produksi tahun 2010 .

Salah satu faktor penyebab turunnya hasil produksi tanaman jagung secara kuantitas adalah akibat gangguan gulma. Gulma sebagai organisme pengganggu tanaman (OPT) termasuk salah satu kendala penting yang harus diatasi dalam peningkatan produksi tanaman jagung. Tingkat masalah yang ditimbulkan oleh gulma pada tanaman jagung cukup beragam, tergantung pada jenis tanah, suhu, ketinggian tempat, cara tanam, pengelolaan air, dan teknik pengendalian gulma. Tanaman jagung cenderung berproduksi tinggi bila bebas gulma selama pertumbuhannya (Moenandir J., 1993). Usaha untuk mengatasi masalah gulma pun dilakukan dengan beragam cara meliputi, pengendalian secara fisik dengan cara manual dan mekanis, pengendalian secara kimiawi dengan herbisida, dan pengendalian kultur teknis dengan penanaman bibit unggul, mengatur waktu pemupukan, takaran pupuk, jarak tanam, dan jenis pupuk yang diberikan.

Secara umum gulma yang ditemukan pada tanaman budidaya dikelompokan dalam tiga golongan, yaitu golongan teki, rerumputan dan berdaun lebar. (Suryaningsih, 2011) bahwa gulma dapat menurunkan hasil tanaman tomat sampai $50 \%$. Masing-masing golongan memiliki karakter yang berbeda, baik dalam segi morfologi maupun ekologinya. Meskipun golongan gulma berdaun lebar memiliki kesamaan dalam beberapa hal, tetapi setiap spesies memiliki perbedaan ciri 
morfologi dan ekologi yang berbeda. Dengan adanya perbedaan itu, boleh jadi pendekatan cara pengendaliaan juga berbeda. Ada beberapa spesies gulma berdaun lebar yang sering ditemukan pada pertanaman jagung di Kabupaten Kutai Timur, namun sampai saat ini belum ada laporan secara resmi mengenai spesies apa saja yang ada. Berdasarkan uraian di atas, dan dalam upaya mengetahui mengenai keanekaragaman jenis gulma berdaun lebar, sehingga dilakukan penelitian tentang keanekaragaman jenis gulma berdaun lebar pada pertanaman jagung di Kabupaten Kutai Timur.

\section{BAHAN DAN METODE}

Penelitian ini menggunakan benih jagung manis bonanza, pengambilan data di lapangan dilakukan pada saat 40 hari setelah pengolahan tanah atau pada saat tanaman jagung berumur 39 hst. Peletakan petak sampel secara sistematik ke seluruh areal tanpa memperhatikan kondisi populasi gulma pada tempat penelitian, petak-petak sampel diletakan pada 9 titik yang berbeda dengan ukuran $2 \times 2 \mathrm{~m}$. Spesies gulma yang ditemukan pada setiap petak sampel melalui pengamatan secara visual dan perhitungan jumlah populasi gulma dijadikan herbarium guna diidentifikasi lebih lanjut (Melati, 2008). Analisis data dilakukan dengan menggunakan analisis kuantitatif terhadap beberapa parameter yaitu, Kerapatan Relatif (KR), Frekuensi Relatif (FR) dan Dominansi Relatif (DR) yang tergabung dalam Indeks Nilai Penting (INP), dan Standar Dominansi Rasio (SDR).

Kerapatan Mutlak (KM), yaitu dapat dirumuskan :

$$
\mathrm{KM}=\frac{\text { Jumlah Suatu Spesies }}{\text { Luas Total Petak Sampling }}
$$

Kerapatan Relatif (KR), yaitu dapat dirumuskan :

$$
\begin{gathered}
\% \mathrm{KR}=\frac{\mathrm{KM} \text { Suatu Spesies }}{\text { Total KM seluruh Spesies }} \times 100 \% \\
\text { Frekuensi Mutlak (FM), yaitu dapat }
\end{gathered}
$$
dirumuskan :

$$
\mathrm{FM}=\frac{\text { Jumlah Plot yang Mempunyai Suatu Jenis }}{\text { Jumlah Seluruh Plot Pengamatan }}
$$
dirumuskan :

$$
\% \mathrm{FR}=\frac{\text { FM suatu spesies }}{\text { Total FM Seluruh Spesies }} \times 100 \%
$$

Dominansi Mutlak (DM), yaitu dapat dirumuskan :

$$
\mathrm{DM}=\frac{\text { Jumlah suatu spesies }}{\text { Jumlah seluruh spesies }}
$$

Dominansi Relatif (DR), yaitu dapat dirumuskan :

$$
\begin{gathered}
\% \mathrm{DR}=\frac{\text { DM suatu spesies }}{\text { Total DM seluruh spesies }} \times 100 \% \\
\text { Indeks Nilai Penting (INP), yaitu dapat }
\end{gathered}
$$
dirumuskan :

$$
\mathrm{INP}=\% \mathrm{KR}+\% \mathrm{FR}+\% \mathrm{DR}
$$

Standar Dominansi Rasio (SDR), yaitu dapat dirumuskan :

$$
\mathrm{SDR}=\frac{\mathrm{INP}}{3}
$$

\section{Persiapan Lahan}

Lahan yang ditanami berukuran $15 \mathrm{x}$ $40 \mathrm{~m}$ terlebih dahulu dibersihkan dari gulma. Kemudian dibuat sebanyak 31 guludan dengan masing-masing berukuran $15 \times 1 \mathrm{~m}$ dan jarak antar guludan $0,3 \mathrm{~m}$, agar tanaman jagung terhindar dari banjir yang sewaktuwaktu dapat menggenangi lokasi penelitian.

\section{Penanaman}

Penanaman dilakukan dengan menggunakan tugal dengan kedalaman 2-3 $\mathrm{cm}$ pada lahan yang telah disediakan dengan jarak tanam $25 \mathrm{~cm} \times 40 \mathrm{~cm}$. Setelah penanaman, gulma dibiarkan tumbuh secara alami tanpa melakukan pengendalian.

\section{Defenisi Operasional}

Untuk menyamakan persepsi dalam penelitian ini, maka ditetapkan defenisi operasional beberapa istilah sebagai berikut :

Keanekaragaman jenis menunjukkan seluruh variasi yang terdapat pada makhluk hidup antar jenis (interspesies). Gulma adalah tumbuhan yang tidak dikehendaki dan mempunyai pengaruh negatif terhadap tanaman budidaya. Pertanaman jagung merupakan areal yang sementara ditanami jagung. Analisis vegetasi ialah mempelajari atau mengkaji lebih dalam tentang pemecahan masalah mengenai dugaan terhadap beberapa jenis tumbuhan yang tumbuh bersama-sama pada suatu lokasi terdapat interaksi yang erat, baik antar tumbuh-tumbuhan maupun dengan hewan-hewan yang hidup dalam lingkungan tersebut. Kerapatan mutlak merupakan banyaknya individu tumbuhan dinyatakan per satuan luas. Kerapatan relatif adalah persentase kerapatan spesies terhadap kerapatan dari seluruh jenis. Frekuensi mutlak adalah perbandingan banyaknya petak contoh yang ditemui suatu spesies terhadap petak contoh yang dibuat. Frekuensi relatif adalah persentase frekuensi suatu spesies terhadap jumlah frekuensi seluruh spesies. Dominansi mutlak adalah menunjukan nilai yang dominan suatu jenis dari keseluruhan jenis pada lokasi tertentu. Dominansi relatif adalah persentase dominansi suatu jenis terhadap jumlah dominansi seluruh jenis. Indeks Nilai Penting (INP) ialah menunjukkan dominansi suatu 
spesies dalam suatu tegakan atau areal tertentu. Standar Dominansi Rasio (SDR) adalah nilai standarisasi dominansi suatu spesies.

\section{HASIL DAN PEMBAHASAN}

Terdapat 11 spesies gulma berdaun lebar (Tabel 1) yang terdiri dari 10 famili, yaitu: Rubiaceae dengan dua spesies (Hedyotis corymbosa L. dan Borreria latifolia (Aubl.) K. Sch.), Euphorbiaceae dengan satu spesies (Phyllanthus niruri Klein ex Willd.), Asteraceae dengan satu spesies (Ageratum conyzoides
L.), Sterculiaceae dengan satu spesies (Melochia corchorifolia L.), dengan satu spesies (Portulaca oleracea L.), Scrophulariaceae dengan satu spesies (Lindernia crustacea (L.) F. Muell., Convolvulaceae dengan satu spesies (Ipomoea triloba L.), Capparidaceae dengan satu spesies (Cleome rutidosperma D.C.), Onagraceae dengan satu spesies (Ludwigia hyssopifolia (G. Don) Exel.) dan Lamiaceae dengan satu spesies (Hyptis capitata Jacq). Hasil analisis jenis gulma berdaun lebar pada setiap plot dapat di lihat pada Tabel 1.

Tabel 1. Jenis gulma berdaun lebar yang ditemukan pada setiap plot penelitian

\begin{tabular}{|c|c|c|c|c|c|c|c|c|c|c|c|c|}
\hline \multirow{2}{*}{ No. } & \multirow{2}{*}{ Spesies } & \multirow{2}{*}{ Familia } & \multicolumn{9}{|c|}{ Plot Sampling } & \multirow{2}{*}{ Jumlah } \\
\hline & & & I & II & III & IV & v & VI & VII & VIII & IX & \\
\hline 1 & H. corymbosa L. & Rubiaceae & 38 & 21 & 5 & 7 & 34 & 27 & 12 & 8 & 3 & 155 \\
\hline 2 & P. niruri Klein ex Willd & Euphorbiaceae & 3 & 1 & 7 & 4 & 21 & 6 & 17 & 9 & 12 & 80 \\
\hline 3 & A. conyzoides $\mathrm{L}$. & Asteraceae & 1 & 3 & 12 & 1 & 17 & 4 & 2 & 6 & 3 & 49 \\
\hline 4 & $\begin{array}{l}\text { B. latifolia (Aubl.) K. } \\
\text { Sch. }\end{array}$ & Rubiaceae & 3 & 1 & 2 & 9 & 5 & 4 & 15 & 2 & 7 & 48 \\
\hline 5 & P. oleracea L. & Portulacaceae & 1 & 17 & 0 & 0 & 2 & 5 & 11 & 7 & 5 & 48 \\
\hline 6 & $\begin{array}{l}\text { L. crustacea (L.) F. } \\
\text { Muell. }\end{array}$ & Scrophulariaceae & 0 & 24 & 0 & 9 & 10 & 3 & 0 & 0 & 0 & 46 \\
\hline 7 & I. triloba L. & Convolvulaceae & 0 & 0 & 0 & 5 & 3 & 0 & 0 & 0 & 2 & 10 \\
\hline 8 & M. corchorifolia L. & Sterculiaceae & 0 & 0 & 0 & 3 & 0 & 2 & 0 & 0 & 0 & 5 \\
\hline 9 & $\begin{array}{l}\text { C. rutidosperma } \\
\text { D.C. }\end{array}$ & Capparaceae & 0 & 0 & 0 & 0 & 0 & 3 & 1 & 0 & 0 & 4 \\
\hline 10 & $\begin{array}{l}\text { L. hyssopifolia (G. } \\
\text { Don) Exel. }\end{array}$ & Onagraceae & 0 & 0 & 0 & 0 & 0 & 3 & 1 & 0 & 0 & 4 \\
\hline 11 & H. capitata Jacq. & Lamiaceae & 0 & 2 & 1 & 0 & 0 & 0 & 0 & 0 & 0 & 3 \\
\hline \multicolumn{3}{|c|}{ Total } & 46 & 69 & 27 & 38 & 92 & 57 & 59 & 32 & 32 & 452 \\
\hline
\end{tabular}

Keberadaan gulma (Tabel 2.) berdaun lebar pada lokasi penelitian bersifat heterogen, karena tidak ada satu spesiespun yang nilai dominansinya lebih dari $80 \%$. Menurut Melati (2008), mengatakan bahwa dalam komunitas suatu vegetasi mempunyai sebaran yang kurang atau sama dengan $80 \%$ itu bersifat heterogen $(0-80 \%)$. Terlihat juga bahwa nilai SDR spesies yang tertinggi yaitu, $H$. corymbosa L. $(28,03 \%)$ dari famili Rubiaceae, dan yang terendah yaitu $H$. capitata Jacq. $(1,59 \%)$ dari famili Lamiaceae.

Gulma yang tumbuh mayoritas adalah jenis gulma semusim yang berkembang biak dengan biji, serta mempunyai biji yang banyak dan dormansi biji yang mampu bertahan lama di lahan. Pendominasian gulma $H$. corymbosa L. terjadi karena merupakan gulma yang tumbuh merumpun, pada setiap pohon dapat memproduksi sekitar ratusan biji yang mudah berkecambah setelah matang.
Perkecambahan dapat terjadi pada daerah yang kering maupun yang lembab. Biji dari $H$. corymbosa $L$. dikenal mampu bertahan pada saat lahan diolah atau dibersihkan, dimana biji segera berkecambah setelah tanaman budidaya ditanam dan terus tumbuh sepanjang musim. Selain itu juga dapat menyebar melalui angin, karena mempunyai biji yang relatif ringan.

Biji-biji gulma biasanya banyak ditemukan di atas permukaan tanah atau yang tertimbun di bawah permukaan tanah, umumnya biji gulma dari musim lalu yang dorman akan tumbuh pada musim berikutnya (Madkar dan Kuntohartono, 1986). Hal ini sejalan dengan pendapat (Hasanuddin, 1989), mengatakan bahwa gulma yang mempunyai adaptasi yang tinggi atau mempunyai kemampuan untuk menyesuaikan diri dan tetap hidup pada lingkungan yang tidak menguntungkan. 
Tabel 2. Tingkat Kerapatan, Frekuensi, Dominansi, INP, dan SDR kehadiran gulma berdaun lebar pada pertanaman jagung di Desa Sangatta Selatan.

\begin{tabular}{|c|c|c|c|c|c|c|c|c|c|c|}
\hline No. & Spesies & Jumlah & KM & $\begin{array}{l}\text { KR } \\
(\%)\end{array}$ & FM & $\begin{array}{l}\text { FR } \\
(\%)\end{array}$ & DM & $\begin{array}{l}\text { DR } \\
(\%)\end{array}$ & $\begin{array}{l}\text { INP } \\
(\%)\end{array}$ & $\begin{array}{l}\text { SDR } \\
(\%)\end{array}$ \\
\hline 1 & H. corymbosa L. & 155 & 4,31 & 34,29 & 1,00 & 15,52 & 0,343 & 34,29 & 84,10 & 28,03 \\
\hline 2 & P. niruri Klein ex Willd. & 80 & 2,22 & 17,70 & 1,00 & 15,52 & 0,177 & 17,70 & 50,92 & 16,97 \\
\hline 3 & A. conyzoides $\mathrm{L}$. & 49 & 1,36 & 10,84 & 1,00 & 15,52 & 0,108 & 10,84 & 37,20 & 12,40 \\
\hline 4 & B. Iatifolia (Aubl.) K. Sch. & 48 & 1,33 & 10,62 & 1,00 & 15,52 & 0,106 & 10,62 & 36,76 & 12,25 \\
\hline 5 & P. oleracea L. & 48 & 1,33 & 10,62 & 0,78 & 12,07 & 0,106 & 10,62 & 33,31 & 11,10 \\
\hline 6 & L. crustacea (L.) F. Muell. & 46 & 1,28 & 10,18 & 0,44 & 6,90 & 0,102 & 10,18 & 27,25 & 9,08 \\
\hline 7 & I. triloba L. & 10 & 0,28 & 2,21 & 0,33 & 5,17 & 0,022 & 2,21 & 9,60 & 3,20 \\
\hline 8 & M. corchorifolia L. & 5 & 0,14 & 1,11 & 0,22 & 3,45 & 0,011 & 1,11 & 5,66 & 1,89 \\
\hline 9 & C. rutidosperma D.C. & 4 & 0,11 & 0,88 & 0,22 & 3,45 & 0.009 & 0,88 & 5,22 & 1,74 \\
\hline 10 & $\begin{array}{l}\text { L. hyssopifolia (G. Don) } \\
\text { Exel. }\end{array}$ & 4 & 0,11 & 0,88 & 0,22 & 3,45 & 0,009 & 0,88 & 5,22 & 1,74 \\
\hline 11 & H. capitata Jacq. & 3 & 0,08 & 0,66 & 0,22 & 3,45 & 0,007 & 0,66 & 4,78 & 1,59 \\
\hline & Total & 452 & 12,56 & & 6,43 & & 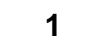 & & & \\
\hline
\end{tabular}

Dominannya gulma tersebut dapat dikarenakan banyaknya biji - biji gulma yang tersimpan pada tanah dalam kedalaman $25 \mathrm{~cm}$ atau lebih. Moenandir (2010) menyatakan bahwa biji gulma yang terbenam dalam tanah yang kemudian terangkat akan tumbuh menjadi gulma dan menjadi pesaing bagi tanaman budidaya. Faktor lain yang mempengaruhi keragaman gulma antara lain ketinggian tempat di atas permukaan laut.

Komposisi gulma berbeda pada pertanaman jagung yang mempunyai ketinggian tempat yang berbeda. Di daerah Kecamatan Blimbing, Malang yang berada pada ketinggian $\pm 444 \mathrm{~m}$ dpl, gulma yang dominan pada pertanaman jagung yaitu Cynodon dactylon (grinting), Althenathera sessilis L. (kremah) dan Echinochloa conona (tuton) (Moenandir, 1993). Rafiuddin et al. (2006) menyatakan bahwa pengerjaan tanah untuk mendapat keadaan olah tanah yang baik mempunyai tujuan memberantas gulma, memasukkan dan mencampurkan sisa tanaman kedalam tanah dan menggemburkan tanah, sehingga terdapat keadaan olah tanah yang diperlukan oleh akar tanaman dan akhirnya akan meningkatkan peredaran udara, infiltrasi air, pertumbuhan akar dan pengambilan unsur hara oleh akar.

Ketinggian tempat lokasi penelitian secara geografis merupakan dataran rendah, sehingga termasuk zona pantai karena berada pada ketinggian 0-60 m dpl. Kondisi udara rata-rata $29^{\circ} \mathrm{C}$ dan banyaknya curah hujan rata-rata 110-114 mm/thn (Monografi, 2011). Ternyata dengan ketinggian dan iklim seperti itu gulma berdaun lebar yang dominan pada pertanaman jagung, yaitu $H$. corymbosa $L$., $P$. niruri Klein ex Willd., dan $A$. conyzoides $\mathrm{L}$.

\section{KESIMPULAN DAN SARAN}

\section{Kesimpulan}

Berdasarkan hasil penelitian bahwa ada 11 spesies dari 10 famili gulma berdaun lebar yang ditemukan, yaitu: $H$. corymbosa $L$. dan B. latifolia (Aubl.) K. Sch. (Rubiaceae), P. niruri Klein ex Willd. (Euphorbiaceae), $A$. conyzoides L. (Asteraceae), M. corchorifolia L. (Sterculiaceae), P. oleracea (L.), L. crustaceae (L.) F. Muell. (Scrophulariaceae), I. triloba L. (Convolvulaceae), C. rutidosperma D.C. (Capparidaceae), L. hyssopifolia (G. Don) Exel. (Onagraceae), dan $H$. capitata Jacq. (Lamiaceae). Gulma tersebut bersifat heterogen, dengan nilai SDR spesies tertinggi, yaitu: $H$. corymbosa L. $(28,03 \%)$, dan terendah yaitu, $H$. capitata Jacq. $(1,59 \%)$.

\section{Saran}

Spesies gulma berdaun lebar yang ditemukan semuanya berkembangbiak dengan biji, sehingga pengendaliannya disarankan untuk memutuskan siklus hidup gulma-gulma tersebut dengan cara mematikannya sebelum memasuki fase generatif. Pengendalian cukup dengan cara manual atau mekanik, supaya dapat meminimalisir biaya produksi (aspek ekonomi) dan dampak terhadap lingkungan (aspek ekologi). Perlu penelitian lebih lanjut mengenai jenis-jenis gulma golongan rerumputan dan teki.

\section{DAFTAR PUSTAKA}

Badan Pusat Statistik Kutai Timur. (2011). Kutai Timur Dalam Anggka 2011. Badan Pusat Statistik Kutai Timur. 
Jurnal Agroteknologi, Vol. 9 No. 2, Februari $2019: 1$ - 6

Hasanuddin. (1989). Tanggapan Tanaman Padi (Oryza sativa L.) Terhadap Kompetisi Gulma-Gulma Dominan. Fakultas Pasca Sarjana Universitas Padjadjaran. Bandung.

Madkar R. O., Kuntohartono T., M. 1986. (1986). Masalah Gulma Dan Cara Pengendaliannya. Himpunan IImu Gulma Indonesia. Bogor.

Melati F. F. (2008). Metode Sampling Bioekologi. Bumi Aksara: Jakarta.

Moenandir, J. 1993. Persaingan Gulma dengan Tanaman Budidaya. Ilmu Gulma Buku III. PT Raja Grafindo Persada. Jakarta. $101 \mathrm{hlm}$.

Moenandir, J. 2010. Persaingan tanaman budidaya dengan gulma. Rajawali press. Jakarta.
Monografi, D. (2011). Desa Sangatta Selatan, Kecamatan Sangatta Selatan, Kabupaten Kutai Timur, Provinsi Kalimantan Timur.

Raifuddin, R. Padjung dan M. Tandi. 2006. Efek sistem olah tanah dan super mikro hayati terhadap pertumbuhan dan produksi jagung. J.Agrivigor 5 (3): 239246.

Suryaningsih, dkk. (2011). Inventarisasi Gulma Pada Tanaman Jagung (Zea mays L.) Di Lahan Sawah Kelurahan Padang Galak, Denpasar Timur, Kodya Denpasar, Provinsi Bali. Jurnal Simbiosis. Jurusan Biologi FMIPA. Universitas Udayana. Bali, (1), 1-8. 
Keanekaragaman Jenis Gulma Berdaun Lebar pada Pertanaman Jagung (Rusdi et al., 2019) 